\title{
Brain Centers Involved in Schizophrenia
}

\section{Felix-Martin Werner}

Institute of Neuroscience of Castilla and León, c/o Euro Akademie Pößneck, Germany

Neuronal pathways in the brain regions involved in schizophrenia, the mesolimbic system, the prefrontal cortex and the hippocampus. In this figure, classical neurotransmitters and neuropeptides with a postsynaptic excitatory impulse (a plus mark) and a presynaptic inhibitory impulse (a minus mark) and the corresponding subreceptors are included. Besides the agonistic (a plus mark) and the antagonistic (a minus mark) effects of the antipsychotic drugs: $\mathrm{ARP}=$ aripiprazole; $\mathrm{ASN}=$ asenapine; $\mathrm{CAP}=$ cariprazine; $\mathrm{CLZ}=$ clozapine; $\mathrm{LUR}=$ lurasidone; OLZ=olanzapine; OSU=OSU-6162; RISP=risperidone; $\mathrm{QTP}=$ quetiapine; $\mathrm{ZIP}=$ ziprasidone are indicated.

\section{Brain centers involved in schizophrenia}

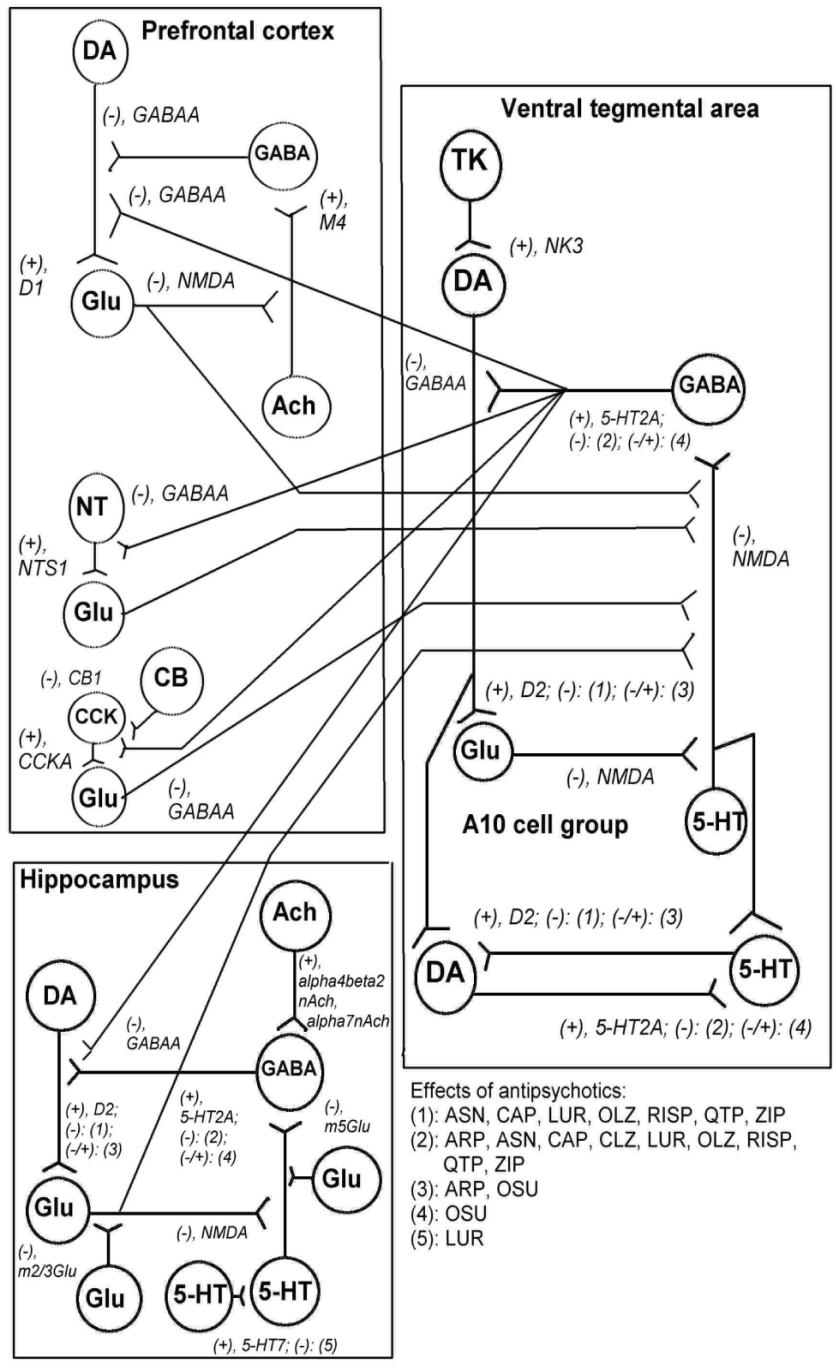

Figure 1: Brain Centers involved in Schizophrenia.
*Corresponding author: Werner FM, Institute of Neuroscience of Castilla and León, c/o Euro Akademie Pößneck, Germany, Tel: 3647505520; E-mail: felixm-werner@versanet.de

Received June 29, 2014; Accepted July 01, 2014; Published July 03, 2014

Citation: Werner FM (2014) Brain Centers Involved in Schizophrenia. J Cytol Histol 5: e101. doi:10.4172/2157-7099.1000i101

Copyright: () 2014 Werner FM. This is an open-access article distributed under the terms of the Creative Commons Attribution License, which permits unrestricted use, distribution, and reproduction in any medium, provided the original author and source are credited. 